\title{
Aphid (Hemiptera: Aphidoidea) population and benefits of their control in spring barley crops in the south-eastern Poland
}

\author{
Liczebność populacji oraz efekty ekonomiczne zwalczania mszyc \\ (Hemiptera: Aphidoidea) w uprawie jęczmienia jarego \\ w Polsce południowo-wschodniej
}

\section{Zdzisław Kaniuczak}

\section{Summary}

The studies on a population and economic effectiveness of insecticides in control of aphids in spring barley were conducted in Boguchwała in the years 2010-2012. The aphid population reached its maximum in the third decade of May or the first half of June, at the flag leaf stage (BBCH 37-41) in the spring barley. In 2012, the aphids were very numerous, reaching an average number of 10.5 individuals per stalk in spring barley. In 2011-2012, all formulations used in the experiments were characterised by a high effectiveness in aphids control in the spring barley. The increase in the barley yield ranged from 4.0 to $9.6 \mathrm{dt} / \mathrm{ha}$. The value of saved barley yield ranged from 304 to 799 PLN per ha. The contribution ratio ranged from 3.4 to 9.1, 6.6 on average. The profitability ratio for barley treatment was 1.1. The percentage cost ratio ranged from 1.5 to 1.6 .

Key words: spring barley; aphids; control; economic indexes

\section{Streszczenie}

Badania nad występowaniem oraz szkodliwością mszyc na jęczmieniu jarym wykonano w latach 2010-2012 w Boguchwale. Maksimum liczebności populacji mszyc stwierdzono w trzeciej dekadzie maja lub pierwszej połowie czerwca, kiedy rośliny były w fazie liścia flagowego (BBCH 37-41). W 2012 roku mszyce wystąpiły w bardzo dużym nasileniu osiągając średnio 10,5 sztuki na źdźble. Wszystkie zastosowane w latach 2011-2012 preparaty wykazały wysoką skuteczność w zwalczaniu mszyc na jęczmieniu jarym. Zwyżka plonu ziarna jęczmienia wyniosła od 4,0 do 9,6 dt/ha. Wartość plonu uratowanego w jęczmieniu jarym wahała się od 304 do 799 PLN/ha. Wskaźnik pokrycia kosztów wyniósł od 3,4 do 9,1, średnio 6,6. Wskaźnik opłacalności zabiegów w jęczmieniu wyniósł 1,1. Procentowy wskaźnik kosztów wahał się od 1,5 do 1,6.

Słowa kluczowe: jęczmień jary; mszyce; zwalczanie; wskaźniki ekonomiczne 


\section{Wstęp / Introduction}

Mszyce obok skrzypionek należą do najważniejszych szkodników zbóż (Versijken 1979; Assmann i wsp. 1988; Mrówczyński i wsp. 2005; Walczak 2010). Masowe występowanie mszyc w dużym stopniu uzależnione jest od przebiegu warunków meteorologicznych. Rozwojowi licznych kolonii tych pluskwiaków sprzyjają lata ciepłe oraz umiarkowanie wilgotne. Wówczas zaledwie w przeciągu kilkunastu dni liczebność może zwiększyć się nawet kilkudziesięciokrotnie (Ruszkowska 2002).

W zasiewach zbóż ozimych i jarych gatunkami mszyc, które mają największe znaczenie praktyczne są: mszyca zbożowa (Sitobion avenae F.), mszyca czeremchowozbożowa (Rhopalosiphum padi L.) oraz mszyca różanotrawowa (Metopolophium dirhodum Walk.) (Szelegiewicz 1968).

Szkodliwe są zarówno osobniki dorosłe, jak i larwy mszyc. Szkodliwość tej grupy owadów związana jest z wysysaniem soków z blaszek liściowych, źdźbeł i kłosów. Przy dużej liczebności, a zwłaszcza w okresach niedoboru wilgoci, ich żerowanie prowadzi do znacznego osłabienia roślin. Groźna jest także szkodliwość pośrednia. Polega ona na przenoszeniu wirusów przez mszyce, w tym groźnego dla zbóż wirusa żółtej karłowatości jęczmienia (BYDV).

W badaniach przeprowadzonych w różnych regionach kraju (Pruszyński i Ruszkowska 1986; Ruszkowska 1987; Bubniewicz i wsp. 1990; Kaniuczak 1990) uzyskano dobrą skuteczność insektycydów w zwalczaniu mszyc oraz osiągnięto zwyżki plonów ziarna pszenicy wynoszące średnio od 0,4 do 0,5 t/ha.

Celem przeprowadzonych badań było prześledzenie dynamiki populacji mszyc na jęczmieniu jarym w warunkach Polski południowo-wschodniej. Wykonano także ocenę skuteczności insektycydów stosowanych do ich zwalczania oraz określono efekty ekonomiczne tych zabiegów.

\section{Materiały i metody / Materials and methods}

Doświadczenia poletkowe zlokalizowano na polach doświadczalnych Podkarpackiego Ośrodka Doradztwa Rolniczego w Boguchwale, w latach 2010-2012. Podstawowe analizy nad szkodliwością i efektami zwalczania szkodników prowadzono na jęczmieniu jarym odmiany Mercada. W okresie wegetacji prowadzono systematyczne, wykonywane raz w tygodniu, analizy liczebności tych owadów na 100 źdźbłach (przeglądając po 25 losowo wybranych roślin w 4 punktach poletka). W oparciu o otrzymane wyniki określono procent zasiedlonych roślin oraz dynamikę liczebności mszyc w sezonie.

Doświadczenia nad skutecznością insektycydów i efektami ekonomicznymi zwalczania mszyc na jęczmieniu jarym prowadzono w latach 2011-2012, metodą bloków losowych w czterech powtórzeniach, na poletkach o powierzchni $15 \mathrm{~m}^{2}$. Do zwalczania mszyc użyto różnych insektycydów: Sumi-Alpha 050 EC (esfenwalerat) w dawce 0,25 1/ha, Fastac 100 EC (alfa-cypermetryna) w dawce 0,1 1/ha oraz Karate Zenon 050 CS (lambda-cyhalotryna) w dawce 0,1 1/ha. Zabiegi wykonano przy użyciu opryskiwacza ciśnieniowego Ap/1 Np, stosując $300 \mathrm{dm}^{3}$ cieczy na hektar.

Skuteczność badanych insektycydów oceniano licząc mszyce przed zabiegiem oraz po upływie 3 i 7 dni po jego wykonaniu według wzoru Hendersona-Tiltona. Po uzyskaniu przez zboże dojrzałości pełnej przeprowadzono zbiór, oznaczono wilgotność i przeliczono plon na $15 \%$ wilgotności. Wyniki analiz plonów ziarna opracowano statystycznie, stosując test Duncana na poziomie $0,05 \%$.

W analizie ekonomicznej opłacalności chemicznego zwalczania szkodników użyto metodę podaną przez Golinowską (2009) wyliczając następujące wskaźniki: $\mathrm{W}_{\mathrm{pk}}$ - wskaźnik pokrycia kosztów, $E_{1}$ - wskaźnik opłacalności zabiegów, $\mathrm{E}_{2}$ - procentowy wskaźnik kosztów. Do obliczenia tych wskaźników przyjęto średnie ceny ziarna jęczmienia, środków ochrony roślin oraz koszt wykonania zabiegu.

\section{Wyniki i dyskusja / Results and discussion}

\section{Przebieg pogody w latach badań}

Warunki pogodowe w latach 2010-2012 przedstawiono w tabeli 1.

W 2010 roku chłodna i deszczowa wiosna sprzyjała rozprzestrzenianiu się chorób i opanowywaniu roślin przez grzyby patogeniczne. W dniach 16-19 maja po intensywnych opadach deszczy wystąiły liczne podtopienia i powodzie. Nadmierne opady w maju, czerwcu i lipcu sprzyjały rozwojowi chorób grzybowych, co zwiększało stopień porażenia roślin, obserwowano zakłócenia w rozwoju roślin jęczmienia jarego.

W 2011 roku, w kwietniu wystąpiło znaczne ochłodzenie, natomiast w maju i czerwcu warunki pogodowe sprzyjały rozwojowi roślin jęczmienia. Taki układ warunków pogodowych korzystnie wpłynął na plonowanie roślin.

W 2012 roku warunki meteorologiczne w rejonie badań były zróżnicowane, niemniej sprzyjały rozwojowi zbóż oraz niektórych szkodników występujących na tych roślinach. Począwszy od kwietnia do pierwszej połowy maja zanotowano stosunkowo dużą liczbę dni z dość niskimi temperaturami (zwłaszcza nocą), które początkowo ograniczały intensywny wzrost roślin. Od drugiej połowy maja wyraźny wzrost temperatury sprzyjał rozwojowi roślin i był korzystny dla rozwoju mszyc na zbożach. Pod względem opadów sezon 2012 należał do stosunkowo suchych, jednak nie odnotowano objawów niedoboru wilgoci na roślinach zbóż. Warunki pogodowe w okresie wiosny sprzyjały rozwojowi roślin jęczmienia jarego oraz zasiedlaniu ich przez szkodniki, w szczególności przez mszyce. 
Tabela 1. Przebieg pogody w Boguchwale w latach 2010-2012

Table 1. Weather conditions in 2010-2012 in Boguchwała

\begin{tabular}{|c|c|c|c|c|c|c|}
\hline \multirow{2}{*}{$\begin{array}{l}\text { Rok } \\
\text { Year }\end{array}$} & \multirow{2}{*}{$\begin{array}{l}\text { Miesiąc } \\
\text { Months }\end{array}$} & \multirow{2}{*}{$\begin{array}{l}\text { Parametry pogodowe } \\
\text { Weather parameters }\end{array}$} & \multicolumn{3}{|c|}{ Dekada - Decade } & \multirow{2}{*}{$\begin{array}{c}\text { Średnia/Suma } \\
\text { miesięczna } \\
\text { Mean/Sum } \\
\text { monthly }\end{array}$} \\
\hline & & & I & II & III & \\
\hline \multirow{4}{*}{2010} & $\begin{array}{l}\text { kwiecień } \\
\text { April }\end{array}$ & $\begin{array}{l}\text { średnia dobowa temperatura powietrza } \\
\text { daily average air temperature }\left[{ }^{\circ} \mathrm{C}\right] \\
\text { opad - rainfall sum }[\mathrm{mm}]\end{array}$ & $\begin{array}{r}7,9 \\
13,9\end{array}$ & $\begin{array}{l}8,4 \\
34,2\end{array}$ & $\begin{array}{l}10,3 \\
0,1\end{array}$ & $\begin{array}{r}8,8 \\
48,2\end{array}$ \\
\hline & $\begin{array}{l}\text { maj } \\
\text { May }\end{array}$ & $\begin{array}{l}\text { średnia dobowa temperatura powietrza daily } \\
\text { average air temperature }\left[{ }^{\circ} \mathrm{C}\right] \\
\text { opad - rainfall sum }[\mathrm{mm}]\end{array}$ & $\begin{array}{l}14,3 \\
43,9\end{array}$ & $\begin{array}{r}13,3 \\
101,9\end{array}$ & $\begin{array}{l}15,0 \\
31,2\end{array}$ & $\begin{array}{r}14,2 \\
177,0\end{array}$ \\
\hline & $\begin{array}{l}\text { czerwiec } \\
\text { June }\end{array}$ & $\begin{array}{l}\text { średnia dobowa temperatura powietrza } \\
\text { daily average air temperature }\left[{ }^{\circ} \mathrm{C}\right] \\
\text { opad - rainfall sum }[\mathrm{mm}]\end{array}$ & $\begin{array}{r}18,0 \\
102,6\end{array}$ & $\begin{array}{l}18,7 \\
20,9\end{array}$ & $\begin{array}{l}16,9 \\
2,6\end{array}$ & $\begin{array}{l}17,8 \\
126,1\end{array}$ \\
\hline & $\begin{array}{l}\text { lipiec } \\
\text { July }\end{array}$ & $\begin{array}{l}\text { średnia dobowa temperatura powietrza } \\
\text { daily average air temperature }\left[{ }^{\circ} \mathrm{C}\right] \\
\text { opad - rainfall sum }[\mathrm{mm}]\end{array}$ & $\begin{array}{l}19,2 \\
73,5\end{array}$ & $\begin{array}{l}23,7 \\
9,2\end{array}$ & $\begin{array}{l}21,3 \\
117,5\end{array}$ & $\begin{array}{l}21,4 \\
200,2\end{array}$ \\
\hline \multirow{4}{*}{2011} & $\begin{array}{l}\text { kwiecień } \\
\text { April }\end{array}$ & $\begin{array}{l}\text { Średnia dobowa temperatura powietrza } \\
\text { daily average air temperature }\left[{ }^{\circ} \mathrm{C}\right] \\
\text { opad - rainfall sum }[\mathrm{mm}]\end{array}$ & $\begin{array}{l}9,5 \\
16,0\end{array}$ & $\begin{array}{l}8,1 \\
12,7\end{array}$ & $\begin{array}{l}13,1 \\
21,3\end{array}$ & $\begin{array}{l}10,2 \\
50,0\end{array}$ \\
\hline & $\begin{array}{l}\text { maj } \\
\text { May }\end{array}$ & $\begin{array}{l}\text { średnia dobowa temperatura powietrza } \\
\text { daily average air temperature }\left[{ }^{\circ} \mathrm{C}\right] \\
\text { opad - rainfall sum }[\mathrm{mm}]\end{array}$ & $\begin{array}{l}9,2 \\
20,6\end{array}$ & $\begin{array}{l}15,0 \\
9,6\end{array}$ & $\begin{array}{l}17,5 \\
19,0\end{array}$ & $\begin{array}{l}13,9 \\
49,2\end{array}$ \\
\hline & $\begin{array}{l}\text { czerwiec } \\
\text { June }\end{array}$ & $\begin{array}{l}\text { średnia dobowa temperatura powietrza } \\
\text { daily average air temperature }\left[{ }^{\circ} \mathrm{C}\right] \\
\text { opad - rainfall sum }[\mathrm{mm}]\end{array}$ & $\begin{array}{l}19,6 \\
29,2\end{array}$ & $\begin{array}{l}17,4 \\
23,2\end{array}$ & $\begin{array}{l}17,2 \\
36,1\end{array}$ & $\begin{array}{l}18,1 \\
88,5\end{array}$ \\
\hline & $\begin{array}{l}\text { lipiec } \\
\text { July }\end{array}$ & $\begin{array}{l}\text { średnia dobowa temperatura powietrza } \\
\text { daily average air temperature }\left[{ }^{\circ} \mathrm{C}\right] \\
\text { opad - rainfall sum }[\mathrm{mm}]\end{array}$ & $\begin{array}{l}16,5 \\
96,5\end{array}$ & $\begin{array}{l}18,8 \\
82,2\end{array}$ & $\begin{array}{l}17,3 \\
55,1\end{array}$ & $\begin{array}{r}17,6 \\
233,8\end{array}$ \\
\hline \multirow{4}{*}{2012} & $\begin{array}{l}\text { kwiecień } \\
\text { April }\end{array}$ & $\begin{array}{l}\text { Średnia dobowa temperatura powietrza } \\
\text { daily average air temperature }\left[{ }^{\circ} \mathrm{C}\right] \\
\text { opad - rainfall sum }[\mathrm{mm}]\end{array}$ & $\begin{array}{r}4,8 \\
15,5\end{array}$ & $\begin{array}{l}9,6 \\
6,2\end{array}$ & $\begin{array}{l}14,8 \\
4,4\end{array}$ & $\begin{array}{l}9,7 \\
26.1\end{array}$ \\
\hline & $\begin{array}{l}\text { maj } \\
\text { May }\end{array}$ & $\begin{array}{l}\text { średnia dobowa temperatura powietrza } \\
\text { daily average air temperature }\left[{ }^{\circ} \mathrm{C}\right] \\
\text { opad - rainfall sum }[\mathrm{mm}]\end{array}$ & $\begin{array}{l}15,3 \\
24,3 \\
\end{array}$ & $\begin{array}{l}12,3 \\
30,1 \\
\end{array}$ & $\begin{array}{r}16,7 \\
1,6 \\
\end{array}$ & $\begin{array}{l}14,7 \\
56,0 \\
\end{array}$ \\
\hline & $\begin{array}{l}\text { czerwiec } \\
\text { June }\end{array}$ & $\begin{array}{l}\text { średnia dobowa temperatura powietrza } \\
\text { daily average air temperature }\left[{ }^{\circ} \mathrm{C}\right] \\
\text { opad - rainfall sum }[\mathrm{mm}]\end{array}$ & $\begin{array}{l}15,8 \\
43,8\end{array}$ & $\begin{array}{l}19,6 \\
31,4\end{array}$ & $\begin{array}{l}19,7 \\
8,4\end{array}$ & $\begin{array}{l}18,3 \\
83,6\end{array}$ \\
\hline & $\begin{array}{l}\text { lipiec } \\
\text { July }\end{array}$ & $\begin{array}{l}\text { średnia dobowa temperatura powietrza } \\
\text { daily average air temperature }\left[{ }^{\circ} \mathrm{C}\right] \\
\text { opad - rainfall sum }[\mathrm{mm}]\end{array}$ & $\begin{array}{r}24,8 \\
6,1\end{array}$ & $\begin{array}{l}18,3 \\
20,1\end{array}$ & $\begin{array}{l}20,8 \\
27,3\end{array}$ & $\begin{array}{l}21,3 \\
53,5\end{array}$ \\
\hline
\end{tabular}

\section{Dynamika populacji mszyc}

Dynamikę populacji mszyc na jęczmieniu jarym przedstawiono na rysunku 1.

W 2010 roku, niesprzyjające warunki meteorologiczne wiosną były jedną z przyczyn małego wystąpienia mszyc na jęczmieniu jarym. Pierwsze osobniki uskrzydlone stwierdzono na roślinach 9 maja. Maksimum występowania form uskrzydlonych przypadło na koniec maja, gdy stwierdzono średnio 0,03 sztuki na źdźble, a mszyce opanowały zaledwie $3 \%$ źdźbeł. Maksimum populacji mszyc na jęczmieniu jarym stwierdzono 6 czerwca, gdy odnotowano średnio 1,4 sztuki na źdźble, a mszyce zasiedlały $61 \%$ źdźbeł.

W 2011 roku, od połowy marca, przez kwiecień, maj i czerwiec, warunki meteorologiczne sprzyjały zasiedlaniu roślin i rozwojowi populacji. Na jęczmieniu jarym maksimum występowania mszyc stwierdzono 30 maja, gdy odnotowano średnio 0,1 sztuki na źdźble, a mszyce opanowały zaledwie $6 \%$ źdźbeł.

W 2012 roku początkowo (w warunkach zmiennej pogody) mszyce zasiedlały rośliny dość wolno, lecz po nastaniu ciepłej pogody nasilenie szybko wzrosło, osiągając 30 maja średnio 4,3 sztuki na źdźble. W tym terminie procent opanowanych źdźbeł wyniósł już $90 \%$. W omawianym roku mszyce wystąpiły w bardzo dużym nasileniu na jęczmieniu jarym. Maksimum populacji odnotowano 6 czerwca, gdy stwierdzono średnio 10,5 sztuki na źdźble i 100\% zasiedlonych źdźbeł.

We wszystkich latach badań, szczególnie w 2012 roku, w okresie, kiedy mszyce osiągnęły maksimum występowania, rośliny były zasiedlane przez afidofagi, głównie 


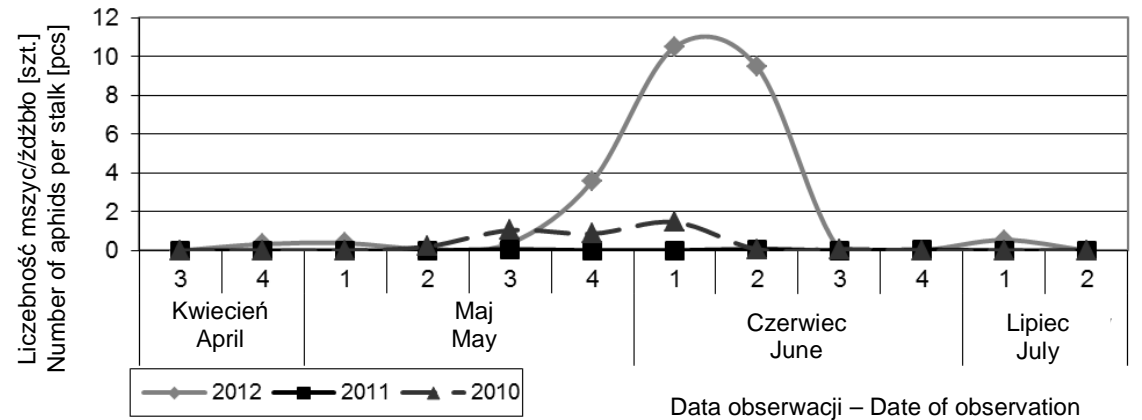

Rys. 1. Dynamika liczebności mszyc na jęczmieniu jarym w latach 2010-2012

Fig. 1. The population dynamics of aphids in spring barley in 2010-2012

przez biedronkowate (Coccinellidae) i bzygowate (Syrphidae), które silnie redukowały populację tych szkodników.

Według Ruszkowskiej (1987) przebieg sezonowej dynamiki rozwoju mszyc na zbożach jest charakterystycznym elementem bionomii. Zjawisko to jest związane głównie ze zróżnicowaną biologią gatunku i zmianami pogody. Gradacje mszycy zbożowej są ściśle związane z okresem dojrzewania zbóż, dlatego tuż przed żniwami załamują się gwałtownie. Ich szczyt letni przypada w okresie kłoszenia, albo po wykłoszeniu.

W swoich badaniach Kaniuczak i Lisowicz (1992) stwierdzili, że nasilenie występowania mszyc na pszenicy ozimej w Polsce południowo-wschodniej charakteryzuje się dużą zmiennością w poszczególnych latach, w zależności od zapasu tych owadów w środowisku, od przebiegu warunków meteorologicznych, a także od obecności afidofagów. Maksimum liczebności populacji na pszenicy ozimej stwierdzono w drugiej lub trzeciej dekadzie czerwca (pod koniec kwitnienia roślin i w okresie wypełniania ziarna). Według cytowanych autorów, w okresie kiedy mszyce uzyskiwały maksimum liczebności, ich kolonie były zasiedlane przez owady drapieżne - głównie biedronkowate i bzygowate, które silnie redukowały populację tych szkodników.

Z badań Ruszkowskiej (2001) wynika, że przy typowym układzie warunków pogodowych i zachowaniu prawidłowego zmianowania populacja mszyc jest w znacznej mierze ograniczana przez licznych wrogów naturalnych, do których obok drapieżców, należą miedzy innymi pasożytnicze błonkówki. Ich obecność przy umiarkowanym nasileniu mszyc, ma istotne znaczenie, jako jeden z czynników ograniczających szkodliwość fitofagów do poziomu tolerancji.

\section{Zwalczanie mszyc i efekty ekonomiczne}

Wyniki dotyczące skuteczności zwalczania mszyc uzyskane w jęczmieniu jarym przedstawiono w tabeli 2., natomiast efekty ekonomiczne zabiegów zestawiono w tabeli 3.

Wszystkie zastosowane preparaty w obu latach badań wykazały wysoką skuteczność w zwalczaniu mszyc na jęczmieniu, zarówno 3, jak i 7 dni po zabiegu $(93,2-$ $100 \%)$. Zwyżka plonu ziarna jęczmienia jarego wahała się od 4,0 do 9,6 dt/ha.
Wartość plonu uratowanego w 2011 roku wyniosła średnio 501 PLN/ha. Koszt ochrony insektycydowej na 1 ha kształtował się na poziomie od 77 do 83 PLN/ha.

Wskaźnik pokrycia kosztów wyniósł średnio 5,6. Wskaźnik ten dla wszystkich kombinacji był wyższy od jedności, a to oznacza, że zabiegi były opłacalne. Wskaźnik opłacalności zabiegów wyniósł od 1,0 do 1,2. Procentowy wskaźnik kosztów wahał się od 1,5 do 1,6\%.

Wartość plonu uratowanego w 2012 roku w jęczmieniu wyniosła od 510 do 799, średnio 677 PLN/ha. Koszt ochrony hektara plantacji jęczmienia jarego przeciw skrzypionkom wahał się od 87 do 89 PLN/ha.

Wskaźnik pokrycia kosztów określający stosunek wartości produkcji uratowanego plonu do kosztów zabiegu w jęczmieniu wyniósł od 5,7 do 9,1, średnio 7,6. Wskaźnik opłacalności zabiegów wyniósł 1,0. Procentowy wskaźnik kosztów wahał się od 1,5 do 1,6.

Mszyce należą do najbardziej uciążliwych szkodników roślin, stąd wymagają stałego monitorowania pojawu i nasilenia występowania na uprawach zbóż oraz chemicznego zwalczania po przekroczeniu progu szkodliwości (Ruszkowska 1987; Walczak 2010).

Według pierwszej z autorek wyniki doświadczeń nad szkodliwością mszyc sugerują, że średnio 5 mszyc na kłos pszenicy ozimej w okresie początku kwitnienia uprawnia do stosowania zabiegów zwalczania. Ta liczba mszyc może spowodować zniżkę plonów o 10-20\% w przypadku, gdy sucha i upalna pogoda umożliwi masowy rozwój tej grupy owadów do okresu dojrzałości ziarna. Według tej samej autorki mszyca zbożowa (Sitobion avenae) wywołuje największe uszkodzenia w okresie pomiędzy fazą strzelania w źdźbło a kłoszeniem zbóż.

Bubniewicz i wsp. (1990) wykonali badania, których celem była ocena przydatności wybranych insektycydów do zwalczania mszycy zbożowej oraz określenie opłacalności chemicznego zwalczania. Większość przebadanych insektycydów wykazała dużą skuteczność działania oraz osiągnęła wysoką efektywność ekonomiczną w postaci istotnego przyrostu plonu ziarna (od 1,7 do 11,8\%). Opłacalność chemicznego zwalczania była od 1 do 20 razy wyższa od kosztów ochrony. Również Kaniuczak (1990) stwierdził, że chemiczne zwalczanie mszyc na pszenicy ozimej spowodowało zwyżkę plonów ziarna od 0,23 do 1,11 t/ha (średnio 0,79 t/ha), a wskaźnik pokrycia kosztów wyniósł średnio 5,9. Zbliżone wyniki w zwalczaniu mszyc 
Tabela 2. Skuteczność insektycydów w zwalczaniu mszyc w jęczmieniu jarym w latach 2011-2012 w Boguchwale

Table 2. The effectiveness of insecticides in control of aphids in spring barley in 2011-2012 in Boguchwała

\begin{tabular}{|c|c|c|c|c|c|c|c|c|}
\hline \multirow{3}{*}{$\begin{array}{l}\text { Lp. } \\
\text { No. }\end{array}$} & \multirow{3}{*}{$\begin{array}{c}\text { Insektycydy } \\
\text { - faza rozwojowa } \\
\text { BBCH 37-41 } \\
\text { Insecticides } \\
\text { - growth stage } \\
\text { BBCH 37-41 }\end{array}$} & \multirow{3}{*}{$\begin{array}{l}\text { Dawka } \\
\text { Dose } \\
{[1 / \mathrm{ha}]}\end{array}$} & \multicolumn{2}{|c|}{$\begin{array}{l}\text { Procent skuteczności } \\
\text { po dniach od zabiegu } \\
\text { Percent of effectiveness } \\
\text { days after treatment }\end{array}$} & \multirow{3}{*}{$\begin{array}{c}\text { MTZ } \\
\text { TGW } \\
{[\mathrm{g}]}\end{array}$} & \multicolumn{3}{|c|}{$\begin{array}{l}\text { Plon } \\
\text { Yield }\end{array}$} \\
\hline & & & \multirow[t]{2}{*}{3} & \multirow[t]{2}{*}{7} & & \multirow[t]{2}{*}{ [dt/ha] } & \multicolumn{2}{|c|}{$\begin{array}{l}\text { plon uratowany } \\
\text { increase in yield }\end{array}$} \\
\hline & & & & & & & [dt/ha] & {$[\%]$} \\
\hline \multicolumn{9}{|c|}{2011} \\
\hline 1. & kontrola - check & - & - & - & 47,15 & 60,3 & - & - \\
\hline 2. & $\begin{array}{l}\text { Karate Zeon } \\
050 \text { CS }\end{array}$ & 0,1 & 98,5 & 100 & 47,80 & 69,9 & 9,6 & 15,9 \\
\hline 3. & $\begin{array}{l}\text { Sumi-Alpha } \\
050 \text { EC }\end{array}$ & 0,25 & 98,0 & 99,0 & 48,39 & 66,7 & 6,3 & 10,5 \\
\hline 4. & Fastac $100 \mathrm{EC}$ & 0,1 & 96,2 & 98,7 & 48,64 & 64,3 & 4,0 & 6,7 \\
\hline \multicolumn{3}{|c|}{$\operatorname{NIR}(0,05)-\operatorname{LSD}(0.05)$} & & & 2,28 & 7,86 & & \\
\hline \multicolumn{9}{|c|}{2012} \\
\hline 1. & kontrola - check & - & - & - & 44,42 & 62,5 & - & - \\
\hline 2. & Karate Zeon 050 CS & 0,1 & 97,8 & 100 & 49,06 & 68,5 & 6,0 & 9,6 \\
\hline 3. & Sumi-Alpha 050 EC & 0,25 & 98,5 & 100 & 48,99 & 71,0 & 8,5 & 13,5 \\
\hline 4. & Fastac $100 \mathrm{EC}$ & 0,1 & 93,2 & 100 & 47,21 & 72,0 & 9,4 & 15,1 \\
\hline \multicolumn{3}{|c|}{$\operatorname{NIR}(0,05)-\operatorname{LSD}(0.05)$} & & & 2,26 & 4,45 & & \\
\hline
\end{tabular}

MTZ - masa tysiąca ziaren - TGW - thousand grain weight

Tabela 3. Efekty ekonomiczne zwalczania mszyc w jęczmieniu jarym w latach 2011-2012 w Boguchwale Table 3. Economic efficiency of insecticide control of aphids in spring barley in 2011-2012 in Boguchwała

\begin{tabular}{|c|c|c|c|c|c|c|c|}
\hline \multirow{2}{*}{$\begin{array}{l}\text { Lp. } \\
\text { No. }\end{array}$} & \multirow{2}{*}{$\begin{array}{c}\text { Insektycydy - faza rozwojowa } \\
\text { BBCH 37-41 } \\
\text { Insecticides - growth stage } \\
\text { BBCH 37-41 }\end{array}$} & \multirow{2}{*}{$\begin{array}{l}\text { Koszt ochrony } \\
\text { Costs } \\
\text { of protection } \\
\text { [PLN/ha] }\end{array}$} & \multicolumn{2}{|c|}{$\begin{array}{l}\text { Plon uratowany } \\
\text { Increase in yield }\end{array}$} & \multicolumn{3}{|c|}{$\begin{array}{l}\text { Wskaźnik } \\
\text { Index }\end{array}$} \\
\hline & & & [dt/ha] & [PLN/ha] & Wpk & $\mathrm{E}_{1}$ & $\mathrm{E}_{2}$ \\
\hline \multicolumn{8}{|c|}{2011} \\
\hline 1. & Karate Zeon 050 CS & 83 & 9,6 & 722 & 8,1 & 1,2 & 1,5 \\
\hline 2. & Sumi-Alpha 050 EC & 78 & 6,3 & 478 & 5,4 & 1,1 & 1,5 \\
\hline 3. & Fastac 100 EC & 77 & 4,0 & 304 & 3,4 & 1,1 & 1,6 \\
\hline \multicolumn{8}{|c|}{2012} \\
\hline 1. & Karate Zeon 050 CS & 89 & 6,0 & 510 & 5,7 & 1,0 & 1,5 \\
\hline 2. & Sumi-Alpha 050 EC & 87 & 8,5 & 722 & 8,2 & 1,0 & 1,5 \\
\hline 3. & Fastac $100 \mathrm{EC}$ & 87 & 9,4 & 799 & 9,1 & 1,0 & 1,6 \\
\hline
\end{tabular}

$\mathrm{W}_{\mathrm{pk}}$ - wskaźnik pokrycia kosztów - cost covering ratio

$\mathrm{E}_{1}$ - wskaźnik opłacalności zabiegów - treatment profitability index

$\mathrm{E}_{2}$ - procentowy wskaźnik kosztów - percentage index of costs

na pszenicy uzyskali także Pruszyński i Ruszkowska (1986).

Wałkowski i Złotkowski (2000) wykonali doświadczenia z jednoczesnym zwalczaniem mszyc i skrzypionek w pszenicy ozimej stwierdzając, że istnieje możliwość jednoczesnego zwalczania tych szkodników, ale efekt zależny jest przede wszystkim od terminu nalotu mszyc na zboża na przełomie maja i czerwca.

\section{Wnioski / Conclusions}

1. W Polsce południowo-wschodniej maksimum liczebności populacji mszyc na jęczmieniu jarym stwierdzono w trzeciej dekadzie maja lub pierwszej połowie czerwca. Rośliny w tym czasie znajdowały się w fazie liścia flagowego (BBCH 37-41). 
2. Chemiczne zwalczanie mszyc na jęczmieniu jarym spowodowało zwyżkę plonu ziarna od 4,0 do 9,6 dt/ha (średnio 7,3 dt/ha).

3. Wskaźnik opłacalności zabiegów pozwolił stwierdzić, że zwyżka plonu ziarna jęczmienia jarego od 100 do $120 \mathrm{~kg} /$ ha równoważy koszty zwalczania mszyc.
4. Wskaźnik pokrycia kosztów wykazał, że każda złotówka wydana na chemiczną ochronę jęczmienia przed mszycami zwraca się od 3,4 do 9,1 raza.

\section{Literatura / References}

Assmann G., Hagele R., Wetzel T. 1988. Untersuchungen zur Okonomie der Bekampfung der Getrideblattlaus (Macrosiphum (Sitobion) avenae F.) in Winterweizen. Nachricht. - Bll. f. Planzenschutz DDR 42 (2): 24-27.

Bubniewicz P., Mrówczyński M., Grala B., Urban M., Banaszak H., Urbanek M., Stępniewski J., Sieńkowski A. 1990. Skuteczność i opłacalność chemicznego zwalczania mszyc występujących na zbożach. Materiały 30. Sesji Nauk. Inst. Ochr. Roślin, cz. 1: 93-105.

Golinowska M. 2009. Ekonomika ochrony roślin w teorii i praktyce. [Economics of plant protection in theory and practice]. Prog. Plant Prot./Post. Ochr. Roślin 49 (1): 23-33.

Kaniuczak Z. 1990. Występowanie i efekty zwalczania mszyc (Aphididae) na pszenicy ozimej w rejonie Przeworska. Materiały 30. Sesji Nauk. Inst. Ochr. Roślin, cz. 2: 37-42.

Kaniuczak Z., Lisowicz F. 1992. Dynamika populacji oraz efekty zwalczania mszyc (Aphididae) w uprawie pszenicy ozimej w południowo-wschodniej Polsce. Prace Nauk. Inst. Ochr. Roślin 34 (1/2): 93-98.

Mrówczyński M., Wachowiak H., Boroń M. 2005. Szkodniki zbóż - aktualne zagrożenia w Polsce. [Cereals pests - current thereats in Poland]. Prog. Plant Prot./Post. Ochr. Roślin 45 (2): 929-932.

Pruszyński S., Ruszkowska M. 1986. Zwalczanie mszyc w uprawach zbóż w Polsce. Materiały 24. Sesji Nauk. Inst. Ochr. Roślin, cz. 1: $85-95$.

Ruszkowska M. 1987. Mszyce występujące na zbożach i ich zwalczanie. Instrukcja wdrożeniowa. Inst. Ochr. Roślin, Poznań, 16 ss.

Ruszkowska M. 2001. Rola naturalnych wrogów w ograniczaniu liczebności jesiennych populacji mszyc na oziminach zbóż $\mathrm{w}$ Wielkopolsce. [The role natural enemies in the control of autumnal aphids population on the winter cereales]. Prog. Plant Prot./Post. Ochr. Roślin 41 (1): 170-174.

Ruszkowska M. 2002. Przekształcenia cyklicznej partenogenezy mszycy Rhopalosiphum padi (L.) (Homoptera, Aphidoidea) - znaczenie zjawiska w adaptacji środowiskowej. Rozpr. Nauk. Inst. Ochr. Roślin 8, 63 ss.

Szelegiewicz H. 1968. Katalog fauny polskiej - Mszyce (Aphidodea). Część 21, Zeszyt 4: 1-316.

Walczak F. 2010. Groźne szkodniki zbóż i terminy ich zwalczania. Wieś Jutra 4 (141): 30-34.

Wałkowski W., Złotkowski J. 2000. Możliwości jednoczesnego zwalczania skrzypionek i mszyc w zbożach. [Plot and practical studies on the using of the modern insecticides to control of the cereal leaf beetles (Lema melanopa L. et L. cyanella Voet.)]. Prog. Plant Prot./Post. Ochr. Roślin 40 (2): 483-487.

Vereijken P.H. 1979. Feeding and multiaplication of thee cereal aphid species and their effect on yield of winter wheat. Agric. Res. Rep. 888, Wageningen: 1-58. 